\title{
Monthly Optimal Reservoirs Operation for Multicrop Deficit Irrigation under Fuzzy Stochastic Uncertainties
}

\author{
Liudong Zhang, ${ }^{1,2}$ Ping Guo, ${ }^{1}$ Shiqi Fang, ${ }^{1}$ and $\mathrm{Mo} \mathrm{Li}^{1}$ \\ ${ }^{1}$ Centre for Agricultural Water Research in China, China Agricultural University, Number 17 Qinghua East Road, \\ Haidian, Beijing 100083, China \\ ${ }^{2}$ College of Water Conservancy, Yunnan Agricultural University, Kunming 650201, China \\ Correspondence should be addressed to Ping Guo; guop@cau.edu.cn
}

Received 11 December 2013; Accepted 6 February 2014; Published 18 March 2014

Academic Editor: Y. P. Li

Copyright (C) 2014 Liudong Zhang et al. This is an open access article distributed under the Creative Commons Attribution License, which permits unrestricted use, distribution, and reproduction in any medium, provided the original work is properly cited.

\begin{abstract}
An uncertain monthly reservoirs operation and multicrop deficit irrigation model was proposed under conjunctive use of underground and surface water for water resources optimization management. The objective is to maximize the total crop yield of the entire irrigation districts. Meanwhile, ecological water remained for the downstream demand. Because of the shortage of water resources, the monthly crop water production function was adopted for multiperiod deficit irrigation management. The model reflects the characteristics of water resources repetitive transformation in typical inland rivers irrigation system. The model was used as an example for water resources optimization management in Shiyang River Basin, China. Uncertainties in reservoir management shown as fuzzy probability were treated through chance-constraint parameter for decision makers. Necessity of dominance (ND) was used to analyse the advantages of the method. The optimization results including reservoirs real-time operation policy, deficit irrigation management, and the available water resource allocation could be used to provide decision support for local irrigation management. Besides, the strategies obtained could help with the risk analysis of reservoirs operation stochastically.
\end{abstract}

\section{Introduction}

Shortage of water resources is a critical constraint for agricultural production in arid and semiarid regions. Because of the changing environment, agricultural water supply is facing the unpredictable challenge. Ashofteh et al. estimated that water demand volume in the future (2026-2039) would increase $16 \%$, while the average long-term annual volume of runoff would decrease $0.7 \%$ [1]. To meet the challenge, reservoirs operation (RO) is important and particularly difficult [2].

Reservoirs operation plays an important role for arid and semiarid areas, especially, when the competition between agricultural and ecological water demand is intense. Agricultural water is critical for food productivity, while ecological water is important to regional sustainable development. Reservoirs operation problems concerned with maximization of irrigation benefits have been emphasized by many researchers since the 1970s [3]. Typical reservoirs operation method was dynamic programming [3-5]. Vedula and Mujumdar [6] integrated the reservoir release and irrigation allocation by using dynamic programming, but they took rainfall and potential evapotranspiration as deterministic inputs. Furthermore, Vedula and Kumar [7] overcome the shortcomings considering the rainfall and inflow as stochastic parameters.

But when the irrigation water is limited to ecological water, the situation is more complicated. Unfortunately, the previous studies mainly focused on irrigation water management. Mujumdar and Ramesh [8] developed a real-time dynamic programming model for optimal crops water allocation and reservoir release, but the framework of the model is deterministic. Moradi-Jalal et al. [2] considered annual crops irrigation water for monthly reservoirs operation and optimal crop pattern. But their research did not consider the relationship between water and crops.

Optimal water allocation for irrigation district is an important issue which has received considerable attention in previous researches. Evers et al. [9] integrated hydrologic model (PRMS) and crop growth simulation model (EPIC) 
for reservoir management options. Dos Santos Teixeira [5] developed a forward dynamic programming (FDP) model for real-time reservoirs operation of irrigation districts. Georgiou and Papamichail [10] aimed to determine optimal irrigation allocation and cropping pattern for multicrops. Prasad et al. 2012 [11] developed a real-time reservoir release decision. Among these studies, crop yield was critical data for decision objective. There were two ways to determine crop yield: (1) estimated by average production per unit area or per cube water [12] and (2) calculated through water production function $[6,11,13]$.

However, in real-world problem the source of water could be groundwater and surface (reservoir) water. Then the problem becomes more complicated to identify the most efficient strategies for the whole system. Reichard [14] applied a stochastic simulation optimization model for Santa ClaraCallcguas Basin surface water-groundwater management. Vedula et al. [13] optimized multicrop water allocation for a reservoir-canal-aquifer system considering intraseasonal period. As discussed above, previous researchers just considered two issues among reservoirs operation, irrigation district, ecological water requirement, and surface watergroundwater conjunctive use. To approach the real situation, an integrated water allocation model related to these issues was considered.

Another difficulty in the whole system was the uncertainties, including natural factors and human triggers. Uncertainties in reservoir and irrigation system caused by river inflows and crops requirement had been discussed from different aspects [1, 15-18]. Karamouz and Vasiliadis [15] forecasted the stream flows by Bayesian stochastic dynamic programing $(B S D P)$ with different conditional probabilities. Teegavarapu and Simonovic [16] handled the imprecise loss function for short time reservoirs operation under fuzzy environment. Seifi and Hipel [19] presented a stochastic model to deal with the stochasticity of inflows under multiple inflow scenarios. Chang et al. [18] combined grey system with fuzzy stochastic dynamic programming. Although uncertainty was considered, the reliability of satisfying (or risk of violating) cannot be reflected. Then Azaiez et al. [20] applied chance constraint to explain the potential benefits of groundwater saving.

But these methods cannot handle dual uncertainties presented as linkage between fuzzy and probability distribution. To handle this problem, Guo and Huang [21] developed a two-stage fuzzy chance-constraint programming for water resources management. In a similar fashion, if adequate samples of historic reservoir inflow date were obtained, then different reservoir inflow levels distributed as randomness distribution. If the total reservoir release water cannot be met, chance-constraint programming can be applied to obtain the expected net benefits [22]. Nevertheless, in the progress of $R O$, alternations were made by decision makers with different goals; probabilities of different inflow levels could not exactly reflect randomness of inflows alone [23]. Thus, the probabilities may own the fuzzy information based on the decision maker's judgment, leading to fuzzy stochastic characteristic.

In this paper, an optimization model for deficient irrigation water allocation under uncertainties was developed.
The model is combined with ground-surface water joint-use model, monthly reservoirs operation model, and multicrop irrigation model. Fuzzy stochastic characteristic was represented as fuzzy probability, reflecting the risk of reservoir release water and necessity of dominance $(N D)$ was considered to illustrate it. Reservoir water and groundwater were integrated as interactive resources for both irrigation districts and ecological water. Irrigation water was calculated through Jensen model under deficit irrigation condition.

\section{Model Formulation}

The available water resources mainly come from the mountainous runoff in typical inland area of China. According to the characters of water resources of inland river system, as shown in Figure 1, the watershed can be divided into two parts, runoff formation and disappear areas. Accumulated water flows into mountainous river for water utilization in the plain region. Several reservoirs located mainly in the mountain river and some of the water was used for irrigation, but the rest leaked in the piedmont plain as groundwater recharge. Groundwater was pumped for agricultural irrigation once more and the surplus water needs to meet the ecological water demand of downstream meanwhile. The water resources transformation process leads to efficient water development pattern and the water recycle is improved. However excessive development scale and unreasonable allocation of water resources can cause the overextraction of groundwater and deterioration of the environment.

At present, maximum utilization of water resources is very important because of the shortage of water resources. To optimize water resources considering exploitation and replenishment balance of groundwater for upstream and downstream users, the current study was used to simulate multiperiod reservoirs operation and multicrop irrigation optimization. The objective is to maximize the total crop yields of the entire irrigation districts.

This model can be written as follows and the meanings of parameters are listed in the Nomenclature section. All of variables are nonnegative:

$$
\begin{aligned}
\operatorname{Max} F= & \sum_{k=1}^{K} \sum_{n=1}^{N}\left[Y_{\max }^{n} \prod_{t=1}^{T}\left(\frac{\mathrm{ET}_{t}^{k, n}}{\mathrm{ET}_{t \max }^{n}}\right)^{\lambda_{t}^{n}} \times A^{k, n}\right] \\
& +\sum_{i=1}^{I} \sum_{n=1}^{N}\left[Y_{\max }^{n} \prod_{t=1}^{T}\left(\frac{\mathrm{ET}_{t}^{i, n}}{\mathrm{ET}_{t \max }^{n}}\right)^{\lambda_{t}^{n}} \times A^{i, n}\right] .
\end{aligned}
$$

The expected crop yields are estimated by deficit irrigation crop water production function. The water production function can be used to tackle the irrigation management. We divide the crop planting stages into monthly periods. The crop's monthly water consumption is the decision variable in the model. The deficit irrigation Jensen model [24] is introduced to reflect crop yields linked to sensitivity of water shortage. Sufficient water requirement of crop can lead to maximum crop yields, and water deficit in different stages may reduce the actual crop production in different degrees. 


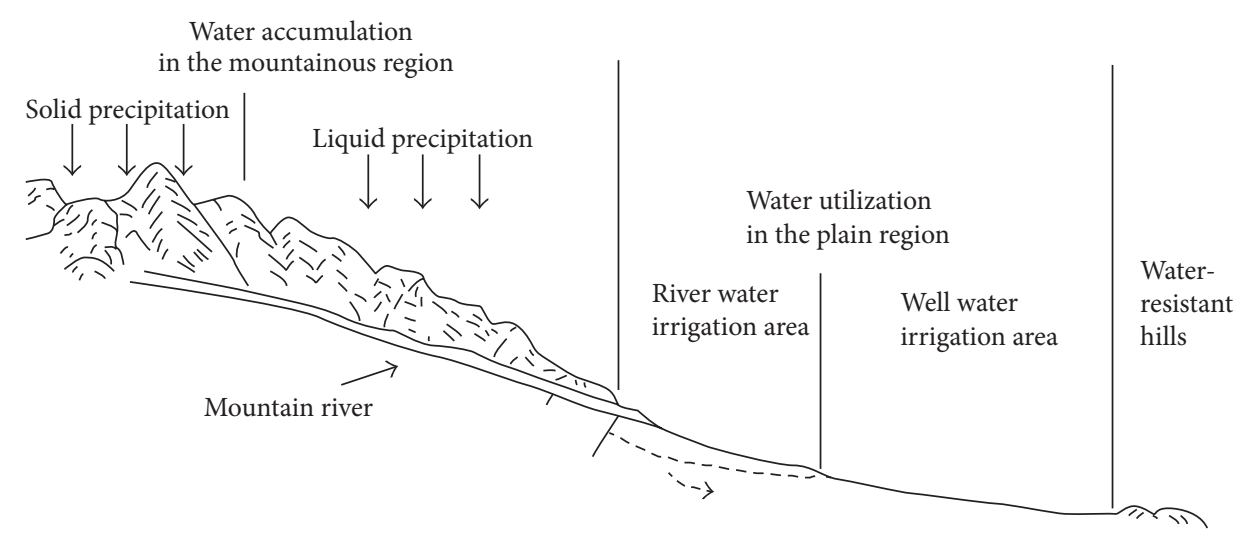

FIGURE 1: The relationship of water resources transformation in arid inland area.

Subject to: Avoiding large water deficit during the period of crop water consumption and not exceeding maximum evapotranspiration constraints,

$$
\begin{aligned}
& 0.6 \mathrm{ET}_{t \text { max }}^{n} \leq \mathrm{ET}_{t}^{k, n} \leq \mathrm{ET}_{t \text { max }}^{n}, \\
& 0.6 \mathrm{ET}_{t \text { max }}^{n} \leq \mathrm{ET}_{t}^{i, n} \leq \mathrm{ET}_{t \text { max }}^{n} .
\end{aligned}
$$

Considering the balance equation of the reservoirs located in the mountain pass of the rivers,

$$
V_{t}^{k}=V_{t-1}^{k}+I_{t}^{k}-R_{t}^{k}-O_{t}^{k}-E_{t}^{k}
$$

Reservoirs overflow constraint is expressed as follows. In each planning time period, accumulated water in the mountainous region flows into the reservoirs. Part of the water is utilized for the irrigation district. If the available storage of reservoir at the end of time period exceeds total effective capacity, the overflow happens. The 0-1 type integer variables are introduced into the model to decide the overflow of the reservoir, 1 for overflow from reservoir occurring and 0 for not occurring. $M$ is a fixed bigger number:

$$
\begin{gathered}
b_{t}^{k} \leq \frac{V_{t}^{k}}{C^{k}}, \\
O_{t}^{k}-b_{t}^{k} \times M \leq 0 .
\end{gathered}
$$

Reservoir capacity constraint: the available storage of reservoir is less than the effective capacity of reservoir:

$$
V_{t}^{k} \leq C^{k}
$$

In real-world practical problem, we allow proper violations. The constraint is considered as uncertain inputs. A risk of violating may lead to higher benefit and more reasonable management strategy. It is often difficult to define the precise boundary of the constraint due to the fuzzy decision. With reference to Guo and Huang [21], the constraint is shown by the following:

$$
\operatorname{Pr}\left(V_{t}^{k} \leq C^{k}\right) \geq \widetilde{\delta}^{k}
$$

Then, we have

$$
\widetilde{1} V_{t}^{k} \leq C^{k\left(\widetilde{p}_{k}\right)}
$$

where $C^{k\left(\widetilde{p}_{k}\right)}=F_{k}^{-1}\left(\widetilde{p}_{k}\right)$ is given the cumulative distribution function of $C^{k}$ and the probability of violating constraint $k\left(\widetilde{p}_{k}\right) \cdot \widetilde{\delta}^{k}$ is fuzzy tolerance measures $\left(0 \leq \widetilde{\delta}^{k} \leq 1, k=\right.$ $1,2, \ldots, K)$, and $\widetilde{\delta}^{k}=1-\widetilde{p}_{k}$.

Assume that the fuzzy coefficients are considered trapezoidal fuzzy sets. Thus, $\widetilde{1}=(\underline{1}, 1, \overline{1})=(0.8,1.0,1.2)$, indicating that the risk level of the reservoir storage is represented as fuzzy uncertainty. When the lower bound of the coefficient is calculated, reservoir storage water was at a high risk level:

$$
\begin{gathered}
\tilde{p}_{k}=\left(\underline{p}_{k}, p_{k 0}, \bar{p}_{k}\right)=\left(1-\bar{\delta}^{k}, 1-\delta^{k 0}, 1-\underline{\delta}^{k}\right), \\
\tilde{p}_{k}=(1-0.95,1-0.8,1-0.6)=(0.05,0.2,0.4) .
\end{gathered}
$$

It meant that the risk level of the reservoir allowable release water distributed as fuzzy stochastic uncertainty. Utilizing $\alpha$ cut technique, fuzzy parameter under each $\alpha$-cut level can be included within a closed interval. And it is expressed as necessity of dominance $(N D)$ solutions. Consider

$$
\begin{gathered}
((1-\alpha) \underline{1}+\alpha) V_{t}^{k} \leq C^{k^{\left((1-\alpha) \underline{p}_{k}+\alpha p_{k 0}\right)},} \\
(0.8+0.2 \alpha) V_{t}^{k} \leq C^{k^{((1-\alpha) 0.05+\alpha 0.2)} .}
\end{gathered}
$$

In order to ensure sustainable utilization of reservoir, the available storage of reservoir at the ending time period is requested not to be less than the beginning time period:

$$
V_{n}^{k}-V_{0}^{k} \geq 0 \quad k=1,2, \ldots, K .
$$

Water consumption in the irrigation district consists of agricultural water and nonagricultural water including domestic and industrial water. According to the irrigation district population, livestock, and industrial production, nonagricultural water including water conveyance loss can be estimated. 
Multiplying water withdrawal for agriculture by utilization coefficient of irrigation water is irrigation water requirement:

$$
\begin{gathered}
R_{t}^{k}=\mathrm{AW}_{t}^{k}+\mathrm{DW}_{t}^{k}, \\
\mathrm{IR}_{t}^{k}=\mathrm{AW}_{t}^{k} \cdot \eta^{k} .
\end{gathered}
$$

By combining the rainfall with water consumption of crops in river irrigation district during growing stages net irrigation water requirement is calculated as follows:

$$
\mathrm{IR}_{t}^{k}=\sum_{n=1}^{N}\left(E T_{t}^{k, n}-P_{t}^{k, n}\right) \times A^{k, n}
$$

Subtracting seepage and evaporation loss reservoirs overflow flows into the downstream. According to the measuring data, the river water loss is large in river irrigation district:

$$
\mathrm{O}_{t}^{k}=\mathrm{RL}_{t}^{k}+\mathrm{RO}_{t}^{k} \text {. }
$$

The available water resource is utilized firstly in river irrigation district and water conveyance loss is unavailable, such as seepage and evaporation. Meanwhile seepage loss supplies groundwater to well irrigation district. Recharge of groundwater can be written as

$$
\mathrm{GO}_{t}=\sum_{k=1}^{K}\left(\alpha E_{t}^{k}+\beta \mathrm{RL}_{t}^{k}+\gamma \mathrm{AW}_{t}^{k}\left(1-\eta^{k}\right)\right)+\mathrm{GI}_{t}
$$

Groundwater exploitation is not taken in river irrigation district. The recharge of groundwater comes from reservoir seepage, river seepage, irrigation seepage, and the lateral groundwater inflow from mountains. $\alpha, \beta, \gamma$ are groundwater recharge coefficients, respectively. In well irrigation district, groundwater can be regarded as an entire underground reservoir. Through conjunctive use of underground and surface water, the underground water reservoir is mainly supplied from surface water. Groundwater quantity balance can be shown as follows:

$$
\begin{aligned}
\mathrm{VG}_{t}= & \mathrm{VG}_{t-1}+\mathrm{GO}_{t} \\
& +\omega \sum_{k=1}^{K} \mathrm{RO}_{t}^{k}+\sum_{i=1}^{I}\left[\gamma^{\prime} \mathrm{AW}_{t}^{i}\left(1-\eta^{i}\right)\right] \\
& -\sum_{i=1}^{I} R_{t}^{i}-\mathrm{GWD}_{t}-\mathrm{GWO}_{t} .
\end{aligned}
$$

$\omega, \gamma^{\prime}$ are groundwater recharge coefficients of rivers and agricultural irrigation in well irrigation district.

Similarly, the groundwater is pumped for agricultural and nonagricultural purpose in well irrigation district. Net irrigation water requirement is calculated as follows:

$$
\begin{gathered}
R_{t}^{i}=\mathrm{AW}_{t}^{i}+\mathrm{DW}_{t}^{i}, \\
\mathrm{IR}_{t}^{i}=\mathrm{AW}_{t}^{i} \cdot \eta^{i}, \\
\mathrm{IR}_{t}^{i}=\sum_{n=1}^{N}\left(\mathrm{ET}_{t}^{i, n}-P_{t}^{i, n}\right) \times A^{i, n} .
\end{gathered}
$$

In order to ensure the reasonable exploitation of groundwater, annual exploitation does not exceed allowable amount of groundwater:

$$
R_{t}^{i} \leq R_{\max }
$$

After the allocation of water resources in plain region, the rest of the water consists of two parts: the surplus water of rivers and groundwater. Excess underground water overflows for downstream as springs. The surplus water of rivers is written as follows:

$$
\mathrm{RO}_{t}^{\prime}=(1-\varepsilon) \sum_{k=1}^{K} \mathrm{RO}_{t}^{k}
$$

$\varepsilon$ is river loss coefficient in well irrigation district. The demand of downstream should be satisfied. So the surplus water should be more than the minimum ecological water demand:

$$
\mathrm{RO}_{t}^{\prime}+\mathrm{GWD}_{t} \geq W_{\min }
$$

The model reflects the characteristics of water resources repetitive transformation in typical inland rivers irrigation system. Multiperiod reservoirs operation and multicrop irrigation optimization is reflected under water allocation and conjunctive use of ground and surface water.

\section{Case Study}

Shiyang River Basin $\left(101^{\circ} 41^{\prime} \sim 104^{\circ} 16^{\prime} \mathrm{E}, 36^{\circ} 29^{\prime} \sim 39^{\circ} 27^{\prime} \mathrm{N}\right)$ is located in arid and semiarid region in Gansu province, northwest of China, which is a typical inland river basin in Hexi Corridor with an annual precipitation of 150-300 mm and potential evaporation of 1200-2000 mm. Water resources in the basin are scarce and have been overused so that a series of ecological environment problems occurred. As shown in Figure 2, the watershed can be divided into three separate river systems according to hydrogeological units: Dajing River, six rivers, and Xida River. In the six rivers system, there are two main basins, Wuwei and Minqin basins. Wuwei Basin was selected as the study area to illustrate the monthly reservoirs operation for multicrop irrigation optimization model under dual uncertainties.

The major water supply of the study area originates from the southern part of the Qilian Mountain and there are six tributaries of the Shiyang River, that is, the Gulang, Huangyang, Zamu, Jinta, Xiying, and Donghe rivers. Some reservoirs are built to regulate water resources in the mountain pass of the rivers except Zamu River. There are six river irrigation districts corresponding to the six rivers, respectively: Gulang $(G L)$, Huangyang $(H Y)$, Zamu $(Z M)$, Jinta $(J T)$, Xiying $(X Y)$, and Donghe $(D H)$ irrigation districts which are located in the south of Wuwei Basin. The available water resource is utilized in river irrigation districts and flows into the northern well irrigation districts. There are four well irrigation districts in the north of the basin: Qingyuan $(Q Y)$, Jingyang $(J Y)$, Yongchang $(Y C)$, and Qinghe $(Q H)$ irrigation districts. The surplus water resources flow into the downstream Minqin Basin. 


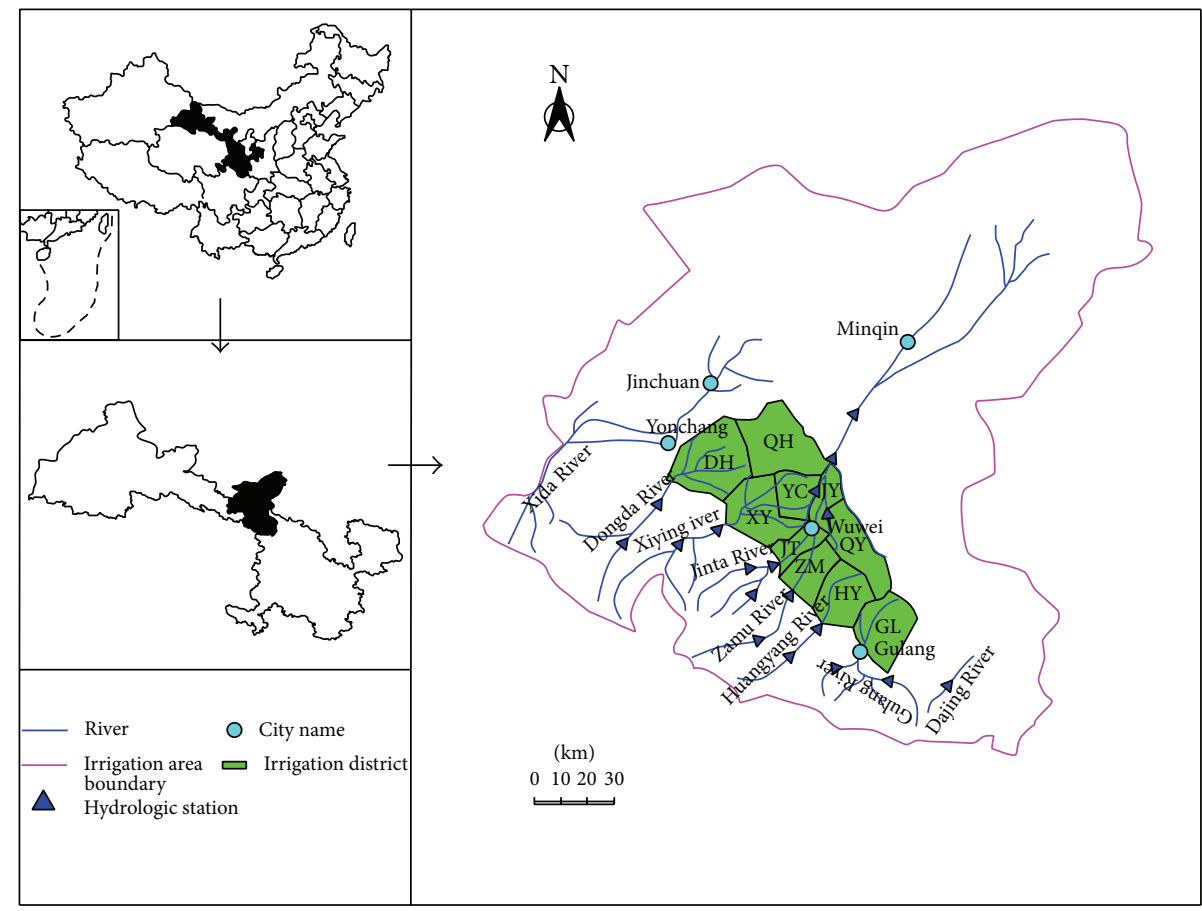

FIGURE 2: The study area.

The dynamic transformation of water resources in river basin complicates the water cycle process. The extensive agriculture development and improper water resources allocation lead to environmental deterioration. The research of Shiyang River Basin water resources transformation was significant to provide decision support for local irrigation managements and agricultural producers.

Because of lower precipitation and higher evaporation, runoff generation is different in Wuwei Basin. The basic water demand of crop growth may not be met. Mountainous runoff is the main source for the crop irrigation. Figure 3 shows the comparison of precipitation and reference crop evapotranspiration $\left(\mathrm{ET}_{0}\right)$. $\mathrm{ET}_{0}$ is only related to local meteorological conditions. $\mathrm{ET}_{0}$ and crop coefficients will be adapted to estimate crop water requirement which is the foundation of irrigation water management. Long-term average annual precipitation is $176 \mathrm{~mm}$ while long-term average annual $\mathrm{ET}_{0}$ is $1008 \mathrm{~mm}$ : however, crop water requirement is larger than $\mathrm{ET}_{0}$.

As mentioned above, mountainous runoff allocation is a critical factor for entire irrigation districts benefits. Runoff statistical study is used to analyze the data from 1955 to 2009 and the six rivers monthly runoff of $2000(P=50 \%)$ as shown in Table 1 is selected as the model inflow data.

The reservoirs total effective storages in the mountainous pass of rivers are 14520, 56440, 16260, 24000, and 80000 $\times 10^{3} \mathrm{~m}^{3}$ corresponding to Gulang, Huangyang, Jinta, Xiying, and Donghe. The annual losses of the reservoirs are approximately $900,3300,1000,3300$, and $2400 \times 10^{3} \mathrm{~m}^{3}$, respectively. In the model, the reservoir is not built on Zamu river, when $k=4, V_{t}^{k}$ and $E_{t}^{k}$ is equal to zero. Beside irrigation district water withdrawal the mountainous runoff flows into

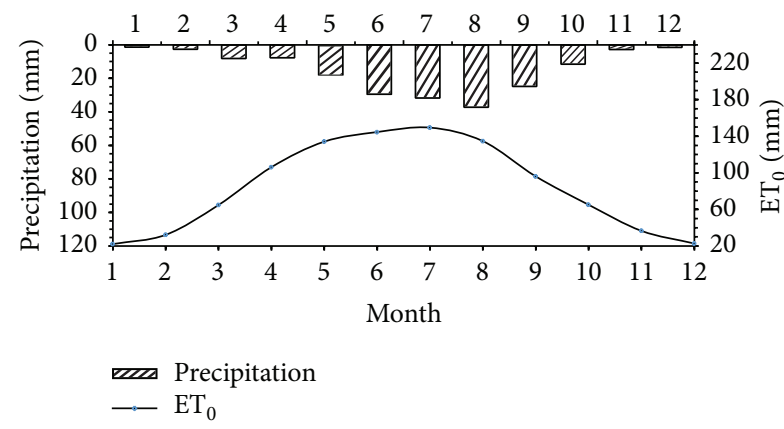

FIGURE 3: The comparison of precipitation and $\mathrm{ET}_{0}$ of the study area.

the downstream river. The balance equation is rewritten as follows:

$$
I_{t}^{k}=R_{t}^{k}+O_{t}^{k}
$$

Irrigation district water withdrawal covers agricultural and nonagricultural purposes, and crop irrigation water is the majority of the agricultural water. The main planting crops in these irrigation districts are wheat, maize, potato, flax, and melon. Growing periods of main crops last from March to September. Irrigated crop area of each irrigation district is shown in Table 2.

The present irrigation method is a traditional model that manages surface irrigation to meet the high yield crop irrigation water requirement which leads to unreasonable water allocation between upstream and downstream users. Because of the scarcity of water resources, deficit irrigation is necessary in the study area. The Jensen model has been 
TABLE 1: The monthly runoff of the six rivers in $2000(P=50 \%)$.

\begin{tabular}{|c|c|c|c|c|c|c|c|c|c|c|c|c|}
\hline \multirow{2}{*}{ River index } & \multicolumn{12}{|c|}{ Monthly runoff $\left(\mathrm{m}^{3} / \mathrm{s}\right)$} \\
\hline & Jan. & Feb. & Mar. & Apr. & May & Jun. & Jul. & Aug. & Sep. & Oct. & Nov. & Dec. \\
\hline Gulang & 0.52 & 0.88 & 0.97 & 1.81 & 3.09 & 2.25 & 3.12 & 5.06 & 5.05 & 2.74 & 1.83 & 1.13 \\
\hline Huangyang & 1.46 & 1.29 & 1.90 & 2.84 & 3.05 & 5.05 & 2.46 & 9.95 & 9.88 & 2.97 & 1.86 & 1.90 \\
\hline Zamu & 0.93 & 0.73 & 1.99 & 4.59 & 8.05 & 14.60 & 8.83 & 17.10 & 16.20 & 7.64 & 3.16 & 2.08 \\
\hline Jinta & 0.54 & 0.38 & 0.61 & 1.07 & 2.99 & 13.30 & 7.84 & 10.60 & 6.89 & 2.46 & 0.90 & 1.01 \\
\hline Xiying & 1.38 & 1.08 & 2.57 & 4.94 & 11.70 & 19.30 & 18.10 & 25.00 & 21.20 & 7.25 & 3.27 & 2.79 \\
\hline Donghe & 3.78 & 3.80 & 4.47 & 6.08 & 10.32 & 17.41 & 15.41 & 18.55 & 14.30 & 6.93 & 5.03 & 3.86 \\
\hline
\end{tabular}

TABLE 2: The irrigated crop area of each irrigation district.

\begin{tabular}{|c|c|c|c|c|c|}
\hline \multirow{2}{*}{ Irrigation district index } & \multicolumn{5}{|c|}{ Irrigated crop area $\left(\mathrm{hm}^{2}\right)$} \\
\hline & Wheat & Maize & Potato & Flax & Melon \\
\hline GL & 4242.41 & 1288.71 & 1523.88 & 206.95 & 103.47 \\
\hline HY & 8047.64 & 2444.63 & 2890.73 & 392.57 & 196.28 \\
\hline $\mathrm{ZM}$ & 6804.69 & 2067.06 & 2444.26 & 331.94 & 165.97 \\
\hline JT & 4714.45 & 1432.11 & 1693.44 & 229.97 & 114.99 \\
\hline $\mathrm{XY}$ & 13526.99 & 4109.09 & 4858.92 & 659.85 & 329.93 \\
\hline $\mathrm{DH}$ & 12303.28 & 3737.36 & 4419.36 & 600.16 & 300.08 \\
\hline QY & 5357.88 & 1627.56 & 1924.56 & 261.36 & 130.68 \\
\hline JY & 3689.18 & 1120.66 & 1325.16 & 179.96 & 89.98 \\
\hline YC & 5039.17 & 1530.75 & 1810.08 & 245.81 & 122.91 \\
\hline $\mathrm{QH}$ & 6037.39 & 1833.97 & 2168.64 & 294.51 & 147.25 \\
\hline
\end{tabular}

more widely adopted for deficit irrigation water production function which is a crop production stage water consumption model and can be used to calculate staged irrigation water. Crop yield calculation method by Jensen model has the following expression:

$$
Y=Y_{\max } \prod_{i=1}^{n}\left(\frac{\mathrm{ET}_{i}}{\mathrm{ET}_{m i}}\right)^{\lambda_{i}} .
$$

$\lambda_{i}$ is sensitivity index of crop to water deficit. $\mathrm{ET}_{i}$ and $\mathrm{ET}_{m i}$ are staged actual evapotranspiration and maximum evapotranspiration. $Y_{\max }$ is maximum crop yield under sufficient irrigation water condition and it can be obtained by water production function in the whole stages. The previous researchers have provided a large number of experimental data and fitted water production function to estimate $Y_{\max }$, which usually is shown as the following:

$$
Y=a_{1}+b_{1} \mathrm{ET}+c_{1} \mathrm{ET}^{2} .
$$

$a_{1}, b_{1}, c_{1}$ are empirical coefficients fixed by experimental data. The calculation results of $Y_{\max }$ are 8097.82, 11219.43, 26978.29, 2268.16 , and $3057.46 \mathrm{~kg} / \mathrm{hm}^{2}$ corresponding to the main crop.

For reservoirs operation and irrigation management, crop sensitivity to water deficit in irrigation interval is more effective than in growth stage. Kipkorir and Raes [25] have applied Jensen model in irrigation interval. Tsakiris [26] provides a method of estimating crop sensitivity to water deficiency at given time intervals. However, relevant study is not reported in the study area. The Jensen model is fitted in monthly interval in keeping up with the optimization model as shown in Table 3. Effective rainfall in example year is $5.7 \mathrm{~mm}, 0 \mathrm{~mm}, 62 \mathrm{~mm}, 9.3 \mathrm{~mm}, 33.3 \mathrm{~mm}$, and $18.6 \mathrm{~mm}$ corresponding to the period from April to September.

Annual nonagricultural water consumption in the model is estimated through the irrigation district population, livestock, and industrial production which are shown in Table 4.

Parameter determination is important for the optimization results. According to Comprehensive Planning of Shiyang River Basin (2007), utilization coefficient of irrigation water of river irrigation area is 0.65 in Gulang irrigation district, 0.58 in Xiying irrigation district, and 0.54 in Huangyang, Zamu, Jinta, and Donghe irrigation districts; utilization coefficient of irrigation water of well irrigation area is 0.6.

The water of each tributary flows together into Shiyang River minus evaporation and leakage loss. River flow in northern Wuwei Basin is low due to severe leakage. According to the investigation, we take 0.667 for the value of leakage rate.

Complement between the surface water and underground water is obvious in the basin.

Groundwater is not pumped in southern Wuwei Basin. Considering the underground aquifer as a whole groundwater reservoir, sources of its supply are reservoir seepage, river seepage, irrigation seepage, and the lateral groundwater inflow. Under low rainfall and deep groundwater level, groundwater is scarcely recharged by the rainfall according to Ma et al. [27]. Rainfall seepage is ignored in the model. 
TABLE 3: The fitted value of $\mathrm{ET}_{m}(\mathrm{~mm})$ and $\lambda$.

\begin{tabular}{|c|c|c|c|c|c|c|c|c|}
\hline \multirow{2}{*}{ Crop index } & & \multicolumn{7}{|c|}{ Month } \\
\hline & & Mar. & Apr. & May. & Jun. & Jul. & Aug. & Sep. \\
\hline \multirow{2}{*}{ Wheat } & $\mathrm{ET}_{m}$ & 23.54 & 119.29 & 176.03 & 219.21 & 153.23 & 0.00 & 0.00 \\
\hline & $\lambda$ & 0.06 & 0.07 & 0.15 & 0.08 & 0.01 & 0.00 & 0.00 \\
\hline \multirow{2}{*}{ Maize } & $\mathrm{ET}_{m}$ & 0.00 & 27.82 & 70.76 & 112.55 & 171.92 & 129.06 & 23.03 \\
\hline & $\lambda$ & 0.00 & 0.04 & 0.12 & 0.20 & 0.31 & 0.22 & 0.03 \\
\hline \multirow{2}{*}{ Potato } & $\mathrm{ET}_{m}$ & 0.00 & 16.87 & 61.56 & 129.22 & 118.91 & 101.47 & 11.32 \\
\hline & $\lambda$ & 0.00 & 0.01 & 0.03 & 0.07 & 0.06 & 0.05 & 0.00 \\
\hline \multirow{2}{*}{ Flax } & $\mathrm{ET}_{m}$ & 0.00 & 18.49 & 105.02 & 150.06 & 146.19 & 77.90 & 0.00 \\
\hline & $\lambda$ & 0.00 & 0.12 & 0.27 & 0.36 & 0.35 & 0.09 & 0.00 \\
\hline \multirow{2}{*}{ Melon } & $\mathrm{ET}_{m}$ & 0.00 & 0.00 & 51.85 & 62.84 & 125.85 & 68.48 & 21.65 \\
\hline & $\lambda$ & 0.00 & 0.00 & 0.06 & 0.07 & 0.15 & 0.08 & 0.01 \\
\hline
\end{tabular}

TABLE 4: Nonagricultural water of irrigation districts $\left(10^{6} \mathrm{~m}^{3}\right)$.

\begin{tabular}{lcccccccccc}
\hline Irrigation district index & GL & HY & ZM & JT & XY & DH & QY & JY & YC & QH \\
\hline Nonagricultural water & 7.74 & 9.30 & 16.71 & 8.39 & 6.20 & 1.53 & 4.49 & 4.86 & 7.07 & 3.03 \\
\hline
\end{tabular}

The quantity of groundwater supply is calculated by recharged coefficients. Qu et al. [28] estimate reservoir seepage and river seepage recharged coefficients as 0.85 and irrigation seepage as 0.8 .

Calculation results of Yao et al. [29] show that the lateral groundwater inflow is $136 \times 10^{6} \mathrm{~m}^{3}$ and the lateral groundwater outflow is $254 \times 10^{6} \mathrm{~m}^{3}$.

To ensure reasonable water allocation between upstream and downstream users, according to local planning, the available groundwater mining is controlled below $319 \times$ $10^{6} \mathrm{~m}^{3}$ and minimum downstream water requirement is not less than $218 \times 10^{6} \mathrm{~m}^{3}$ under local planning requirements.

\section{Results Analysis}

4.1. Multicrop Deficit Irrigation Management. Deficit irrigation could result in the lower crop yields and reduce the net benefits of the irrigation district. However, it is unavoidable because of water resources shortage. The relation between sensitivity of water deficit and crop water use efficiency was studied through the use of Jensen model.

According to the calculation results of optimal decisionmaking model, deficit irrigation proportions of the five crops in the whole growth stage in river irrigation district are 0.61 , $0.84,0.71,0.60$, and 0.68 , respectively, and in well irrigation district the values are $0.76,1.00,1.00,0.94$, and 0.60 . It indicates that deficit irrigation should be adopted primarily in river irrigation district.

The optimization model can reach crop water requirement in each irrigation interval. As shown in Figure 4, the priority deficit irrigation crops are melon and wheat in well irrigation district. ET is monthly optimal crop water requirements and $\mathrm{ET}_{m}$ is monthly potential crop water requirements. The results can provide multiperiod deficit irrigation management for the agricultural producers.

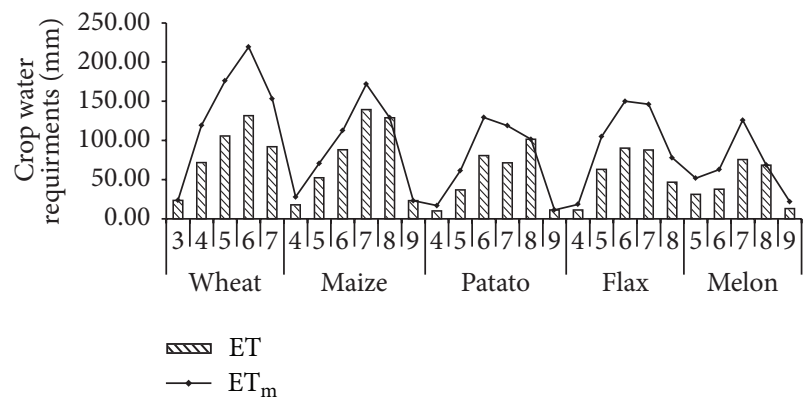

(a) Optimal crop water requirements in river irrigation

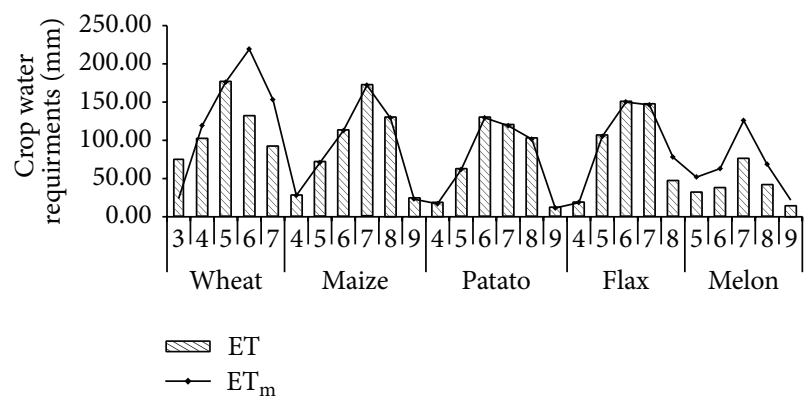

(b) Optimal crop water requirements in well irrigation

FIGURE 4: Results of crop deficit irrigation management.

4.2. Monthly Reservoirs Operation. In the monthly multicrop irrigation system, water resource is mainly obtained from the mountain river. Reservoirs regulation is significant for the water utilization. Reservoirs release and overflow management can be determined by the model. The nonagricultural water demand of each irrigation district among time periods is even, but the primary part of agriculture water demand depends on the crop area and growing periods of crop. 


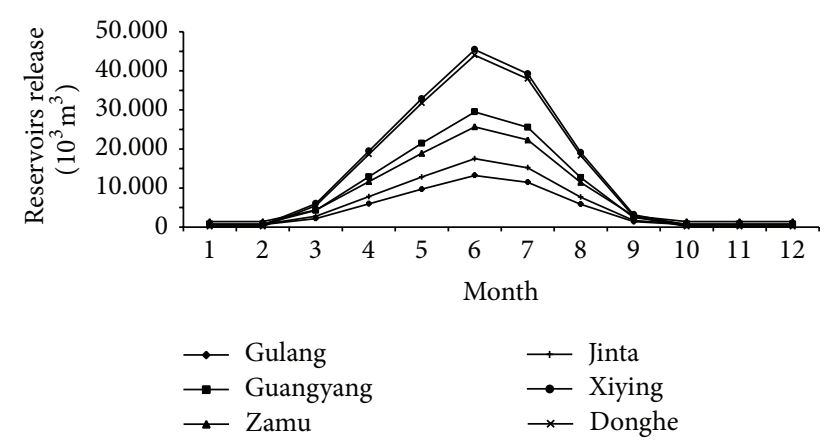

FIGURE 5: Real-time multireservoirs release.

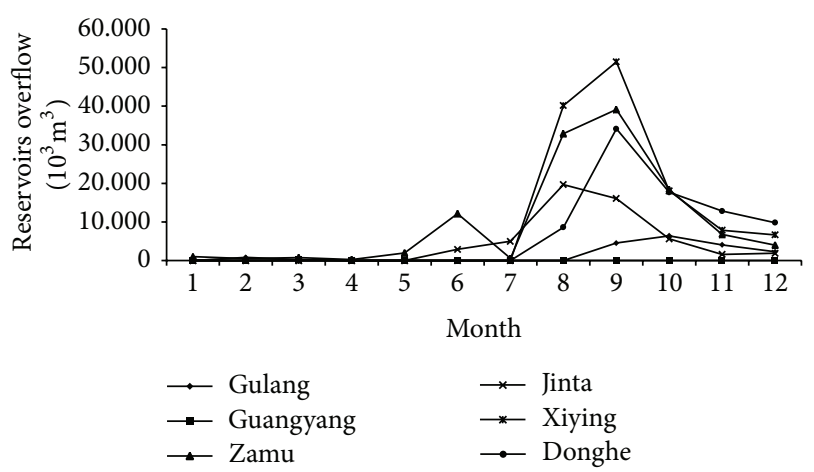

FIGURE 6: Real-time reservoirs overflow.

Total annual runoff of the six rivers is $1145.9 \times 10^{6} \mathrm{~m}^{3}$ and real-time multireservoirs release can be shown in Figure 5. Agricultural water consumption takes most rates in water consumption structure. The maximum water demand occurs in June. Water withdrawal is closely related to irrigation area of each reservoir water-supply zone. The total annual water withdrawal from reservoir is $665.74 \times 10^{6} \mathrm{~m}^{3}$.

To avoid the occurrence of shortage and overflow at the same time period, overflow would not happen unless the reservoir is full storage. Figure 6 shows the real-time reservoirs overflow. Overflow occurred in the period from August to October when irrigation water demand decreased and monthly runoff was still high. The annual reservoirs overflow is $154.51 \times 10^{6} \mathrm{~m}^{3}$. It indicates that mountainous runoff is utilized by river irrigation district. The maximum annual overflow is from Xiying Reservoir with $124.24 \times$ $10^{6} \mathrm{~m}^{3}$, and the minimum overflow is from Huangyang Reservoir with $0.21 \times 10^{6} \mathrm{~m}^{3}$.

\subsection{Recharge Relationship between Surface Water and Under-} ground Water. Wuwei Basin is a typical inland river basin; conjunctive use of surface water and underground water is necessary to the arid irrigation area. To be more efficient in the groundwater management, managers should try to realize recharge relationship between surface water and underground water and determine the available underground water.

In the model, underground water is pumped in the well irrigation district and supply from reservoir seepage,

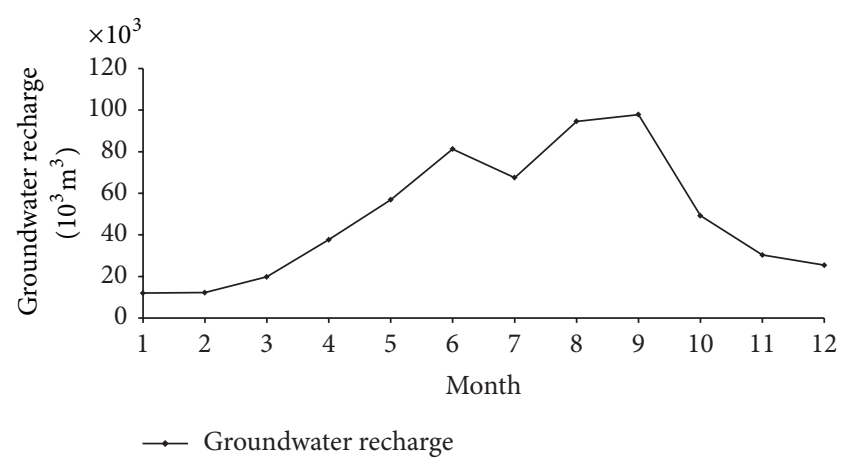

FIgURE 7: Monthly groundwater recharge in the basin.

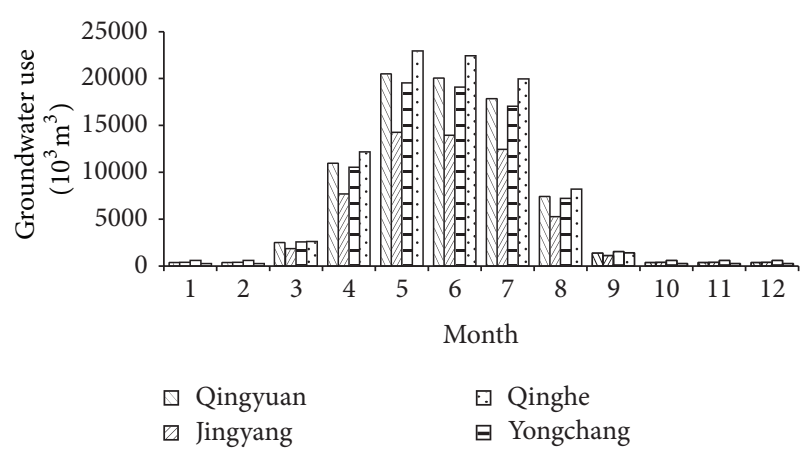

FIGURE 8: Monthly groundwater use in well irrigation district.

river seepage, irrigation seepage, and the lateral groundwater inflow in the southern basin. Figure 7 shows the monthly groundwater recharge of the basin.

As a result of conjunctive use of surface water and groundwater optimization model, the groundwater use in each well irrigation district can be listed in Figure 8, in order to provide decision support for local irrigation management. The major groundwater exploitation is from April to August. Groundwater quantity balance is considered in the model. Groundwater exploitation is less than groundwater recharge, and annual exploitation does not exceed allowable amount of groundwater.

4.4. Fuzzy Stochastic Uncertainty. In real-world practical problem, reservoir capacity is not considered as strictly determinate numbers, and the failure of the constraint is allowed. So the chance-constraint programming is considered to analyse the uncertain constraint of the failure of the limitation of the total reservoir capacity. Proper violation under different risks is studied in the model, which provides selectable management strategies for the decision makers. Necessity of dominance (ND) solutions under three $\alpha$-cut levels are calculated.

As shown in Figure 9, the lower $\alpha$-cut level leads to higher total crop yield. It means that reservoir capacity constraint is loose under lower $\alpha$-cut level and higher violation risk leads to larger system benefit.

In this model, the right hand of the reservoir capacity constraint is allowed to change under the given probabilities. 


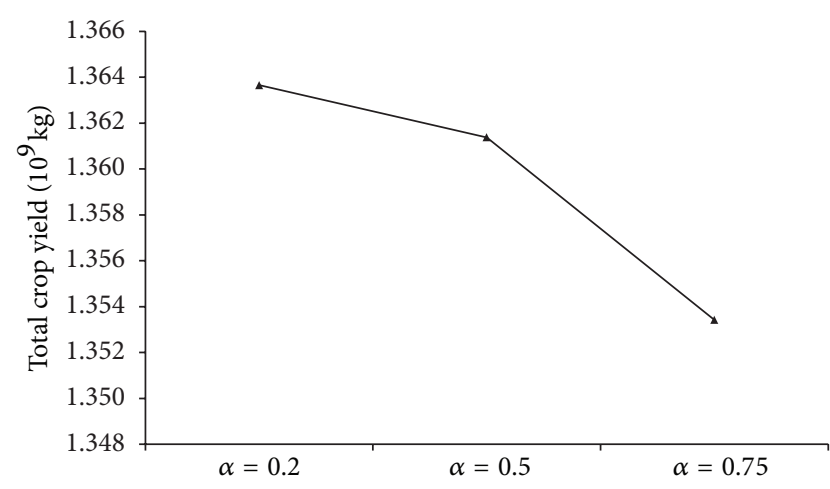

Figure 9: Total crop yield of the entire irrigation districts under different $\alpha$-cut levels.

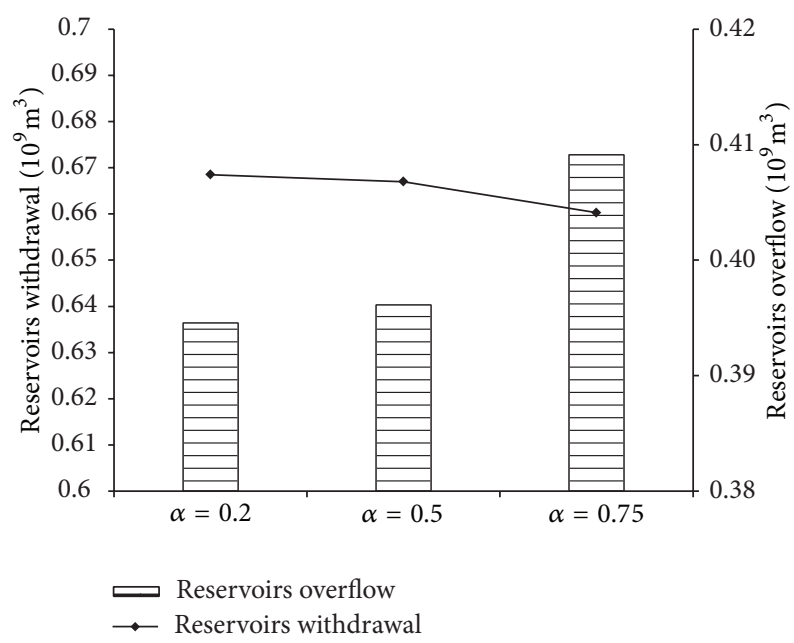

FIGURE 10: Reservoirs withdrawal and overflow under different $\alpha$ cut levels.

As shown in Figure 10, water supply from reservoirs is 0.668 $\times 10^{9} \mathrm{~m}^{3}(\alpha=0.2)$ and the corresponding figure is 0.660 $\times 10^{9} \mathrm{~m}^{3}(\alpha=0.75)$, while water overflow from reservoirs experiences the opposite change.

\section{Conclusions}

In this study, a multicrop irrigation water resources optimization model based on Jensen water production function model for real-time reservoirs operation is proposed. The objective of the model is to achieve the maximum benefit of irrigation areas, considering water stress level of crops and the dynamic characteristic in the irrigation water resources optimal allocation system. The proposed model can provide decision makers with different irrigation water optimal staged allocation schedules (conjunctive of surface water and groundwater) of upstream and downstream and agricultural and nonagricultural water resources, and so forth.

Considering the uncertainties of irrigation water resources management system, fuzzy chance-constraint programming is introduced to the developed model. Necessity of dominance (ND) is adopted to solve fuzzy chance-constraint program, with the membership function of both fuzzy parameters and probabilities being a triangular fuzzy membership function in this study.

The developed model has been applied to Shiyang River Basin, China, to demonstrate the applicability of the developed model. The limited water resources supply, that is, monthly runoff and effective precipitation, the conjunctive use of surface water and groundwater, and the ecological water demand of downstream are considered. As a result, the irrigation water resources optimal allocation schedules for multiple crops of multiple periods of reservoirs operation under different $\alpha$-cut levels are obtained and analyzed. Such results are valuable for local irrigation managements and agricultural producers. Further study will focus on field measurement experiments of some parameters, for example, utilization coefficient of irrigation water, seepage recharged coefficients, and river leakage rate to make the developed model have more practical value.

\section{Nomenclature}

$A^{k, n}: \quad$ Irrigated crop area

$b_{t}^{k}$ : $\quad 0-1$ type integer variables to decide the

overflow of the reservoir

$C^{k}: \quad$ Effective capacity of reservoir

$E_{t}^{k}$ : Reservoir losses

$\mathrm{ET}_{t}^{k, n}:$ Actual crop evapotranspiration

$\mathrm{ET}_{t \max }^{n}$ : Potential maximum crop evapotranspiration

$\lambda_{i}^{n}: \quad$ Sensitive index of the crop to water stress

during the stage

$F: \quad$ Expected crop yields of the entire irrigation districts

$\mathrm{GI}_{t}$ : Lateral groundwater inflow from mountains

$\mathrm{GO}_{t}: \quad$ Recharge of groundwater from river irrigation district

$\mathrm{GWD}_{t}$ : Groundwater supplementary amount for downstream

$\mathrm{GWO}_{t}$ : Lateral groundwater outflow from well irrigation district

$i: \quad$ Well irrigation district index

$I_{t}^{k}$ : Inflow to the reservoir in time period $t$

$\mathrm{IR}_{t}^{k}$ : Net irrigation water requirement

$\mathrm{AW}_{t}^{k}$ : Agricultural water requirement in river irrigation district

$\mathrm{AW}_{t}^{i}: \quad$ Agricultural water requirement in well irrigation district

$\mathrm{DW}_{t}^{k}$ : Nonagricultural water requirement in river irrigation district

$\mathrm{DW}_{t}^{i}$ : Agricultural water requirement in well irrigation district

$k$ : $\quad$ River irrigation district index

$n: \quad$ Crop index

$\mathrm{O}_{t}^{k}$ : Reservoir overflow

$P_{t}^{k, n}: \quad$ Effective precipitation

$R_{\max }$ : Annual allowable amount of groundwater 
$W_{\text {min }}$ : Annual downstream minimum ecological water demand

$R_{t}^{k}$ : Water consumption in the irrigation district

$\mathrm{RL}_{t}^{k}$ : Loss of river

$\mathrm{RO}_{t}^{k}$ : Remaining flow of the rivers

$t$ : $\quad$ Time period index

$V_{t-1}^{k}$ : Reservoir storage at the beginning of time period $t$

$V_{t}^{k}$ : Reservoir storage at the end of time period $t$

$Y_{\max }^{n}:$ Crop maximum yield of crop $\mathrm{n}$ under the condition of full irrigation method

$\mathrm{VG}_{t}$ : Storage capacity of groundwater

$\eta^{k}$ : Utilization coefficient of irrigation water.

\section{Conflict of Interests}

The authors declare that there is no conflict of interests regarding the publication of this paper.

\section{Acknowledgments}

The research was sponsored by the National Natural Science Foundation of China (nos. 41271536 and 51321001) and National High Technology Research and Development Program of China (863 Program) (nO. 2013AA102904).

\section{References}

[1] P. S. Ashofteh, O. B. Haddad, and M. A. Mariño, "Climate change impact on reservoir performance indexes in agricultural water supply," Journal of Irrigation and Drainage Engineering, vol. 139, no. 2, pp. 85-97, 2012.

[2] M. Moradi-Jalal, O. Bozorg Haddad, B. W. Karney, and M. A. Mariño, "Reservoir operation in assigning optimal multi-crop irrigation areas," Agricultural Water Management, vol. 90, no. 1-2, pp. 149-159, 2007.

[3] W. S. Butcher, "Stochastic dynamic programming for optimum reservoir operation1," Water Resources Bulletin, vol. 7, no. 1, pp. 115-123, 1971.

[4] J. R. Stedinger, B. F. Sule, and D. P. Loucks, "Stochastic dynamic programming models for reservoir operation optimization," Water Resources Research, vol. 20, no. 11, pp. 1499-1505, 1984.

[5] A. Dos Santos Teixeira and M. A. Mariño, "Coupled reservoir operation-irrigation scheduling by dynamic programming," Journal of Irrigation and Drainage Engineering, vol. 128, no. 2, pp. 63-73, 2002.

[6] S. Vedula and P. P. Mujumdar, "Optimal reservoir operation for irrigation of multiple crops," Water Resources Research, vol. 28, no. 1, pp. 1-9, 1992.

[7] S. Vedula and D. N. Kumar, "An integrated model for optimal reservoir operation for irrigation of multiple crops," Water Resources Research, vol. 32, no. 4, pp. 1101-1108, 1996.

[8] P. P. Mujumdar and T. S. V. Ramesh, "Real-time reservoir operation for irrigation," Water Resources Research, vol. 33, no. 5, pp. 1157-1164, 1997.
[9] A. Evers, R. Elliott, and E. Stevens, "Integrated decision making for reservoir, irrigation, and crop management," Agricultural Systems, vol. 58, no. 4, pp. 529-554, 1998.

[10] P. E. Georgiou and D. M. Papamichail, "Optimization model of an irrigation reservoir for water allocation and crop planning under various weather conditions," Irrigation Science, vol. 26, no. 6, pp. 487-504, 2008.

[11] A. S. Prasad, N. Umamahesh, and G. Viswanath, "Short-term real-time reservoir operation for irrigation," Journal of Water Resources Planning and Management, vol. 139, no. 2, pp. 149-158, 2012.

[12] A. Afshar, M. A. Marino, and A. Abrishamchi, "Reservoir planning for irrigation district," Journal of Water Resources Planning and Management, vol. 117, no. 1, pp. 74-85, 1991.

[13] S. Vedula, P. P. Mujumdar, and G. Chandra Sekhar, "Conjunctive use modeling for multicrop irrigation," Agricultural Water Management, vol. 73, no. 3, pp. 193-221, 2005.

[14] E. G. Reichard, "Groundwater-surface water management with stochastic surface water supplies: a simulation optimization approach," Water Resources Research, vol. 31, no. 11, pp. 28452865, 1995.

[15] M. Karamouz and H. V. Vasiliadis, "Bayesian stochastic optimization of reservoir operation using uncertain forecasts," Water Resources Research, vol. 28, no. 5, pp. 1221-1232, 1992.

[16] R. S. V. Teegavarapu and S. P. Simonovic, "Modeling uncertainty in reservoir loss functions using fuzzy sets," Water Resources Research, vol. 35, no. 9, pp. 2815-2823, 1999.

[17] X. Li, S. Guo, P. Liu, and G. Chen, "Dynamic control of flood limited water level for reservoir operation by considering inflow uncertainty," Journal of Hydrology, vol. 391, no. 1-2, pp. 124-132, 2010.

[18] F.-J. Chang, S.-C. Hui, and Y.-C. Chen, "Reservoir operation using grey fuzzy stochastic dynamic programming," Hydrological Processes, vol. 16, no. 12, pp. 2395-2408, 2002.

[19] A. Seifi and K. W. Hipel, "Interior-point method for reservoir operation with stochastic inflows," Journal of Water Resources Planning and Management, vol. 127, no. 1, pp. 48-57, 2001.

[20] M. N. Azaiez, M. Hariga, and I. Al-Harkan, "A chanceconstrained multi-period model for a special multi-reservoir system," Computers and Operations Research, vol. 32, no. 5, pp. 1337-1351, 2005.

[21] P. Guo and G. H. Huang, "Two-stage fuzzy chance-constrained programming: application to water resources management under dual uncertainties," Stochastic Environmental Research and Risk Assessment, vol. 23, no. 3, pp. 349-359, 2009.

[22] A. J. Askew, "Chance-constrained dynamic programing and the optimization of water resource systems," Water Resources Research, vol. 10, no. 6, pp. 1099-1106, 1974.

[23] D. Z. Fu, Y. P. Li, and G. H. Huang, "A factorial-based dynamic analysis method for reservoir operation under fuzzy-stochastic uncertainties," Water Resources Management, vol. 27, no. 13, pp. 4591-4610, 2013.

[24] M. E. Jensen, "Water consumption by agricultural plants," Water Deficits and Plant Growth, vol. 2, pp. 1-22, 1968.

[25] E. C. Kipkorir and D. Raes, "Transformation of yield response factor into Jensen's sensitivity index," Irrigation and Drainage Systems, vol. 16, no. 1, pp. 47-52, 2002.

[26] G. P. Tsakiris, "A method for applying crop sensitivity factors in irrigation scheduling," Agricultural Water Management, vol. 5, no. 4, pp. 335-343, 1982. 
[27] J. Ma, Z. Ding, W. M. Edmunds, J. B. Gates, and T. Huang, "Limits to recharge of groundwater from Tibetan plateau to the Gobi desert, implications for water management in the mountain front," Journal of Hydrology, vol. 364, no. 1-2, pp. 128141, 2009.

[28] Y. Qu, S. Ma, and W. Qu, "water resources transformation and development and use model in the arid area of northwest china," Journal of Desert Research, vol. 18, no. 4, pp. 299-307, 1988.

[29] L. Yao, S. Feng, X. Mao, Z. Huo, S. Kang, and D. A. Barry, "Coupled effects of canal lining and multi-layered soil structure on canal seepage and soil water dynamics," Journal of Hydrology, vol. 430-431, pp. 91-102, 2012. 


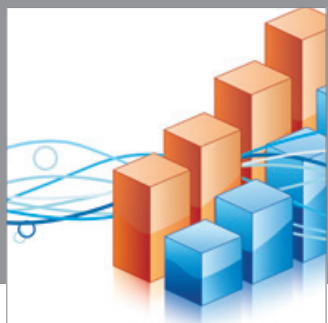

Advances in

Operations Research

mansans

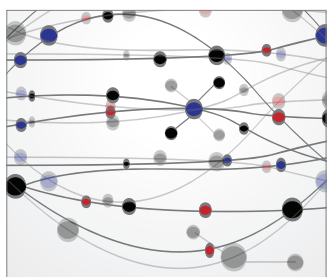

The Scientific World Journal
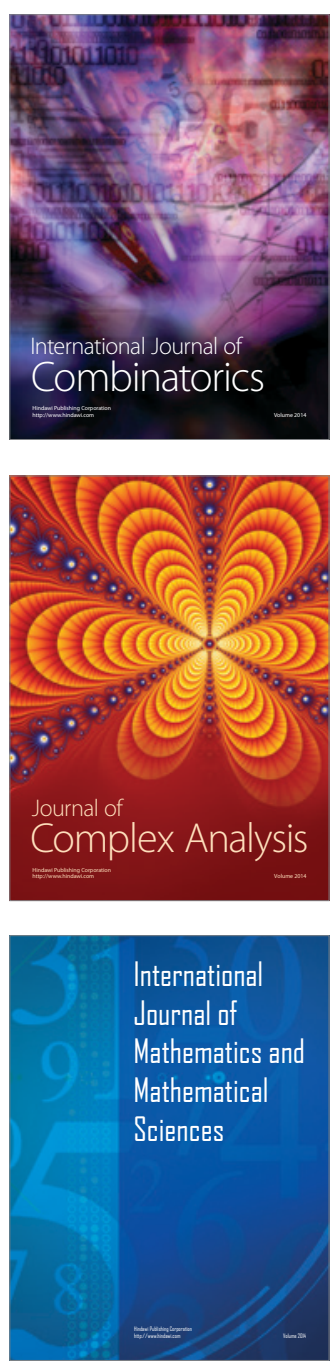
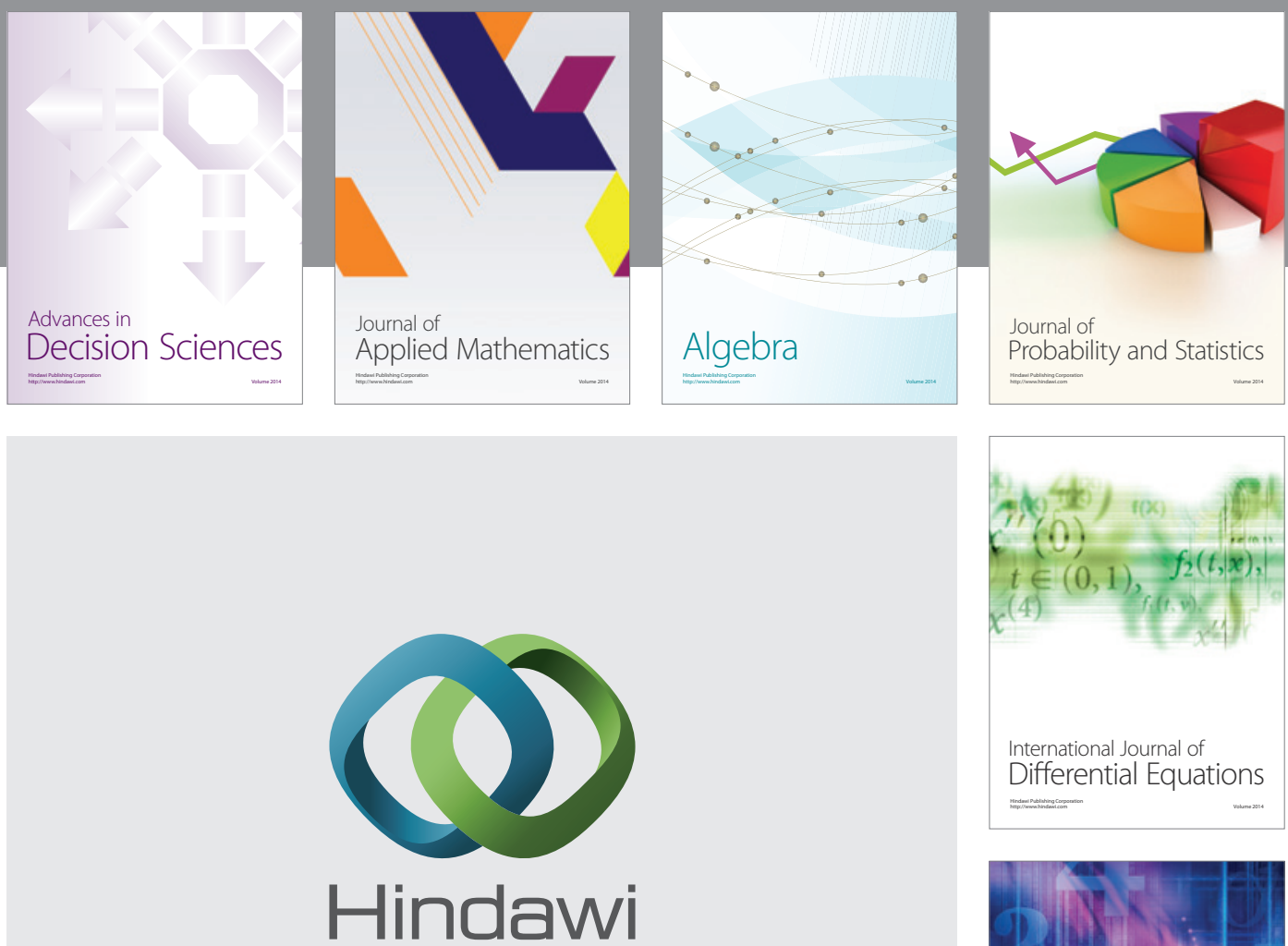

Submit your manuscripts at http://www.hindawi.com
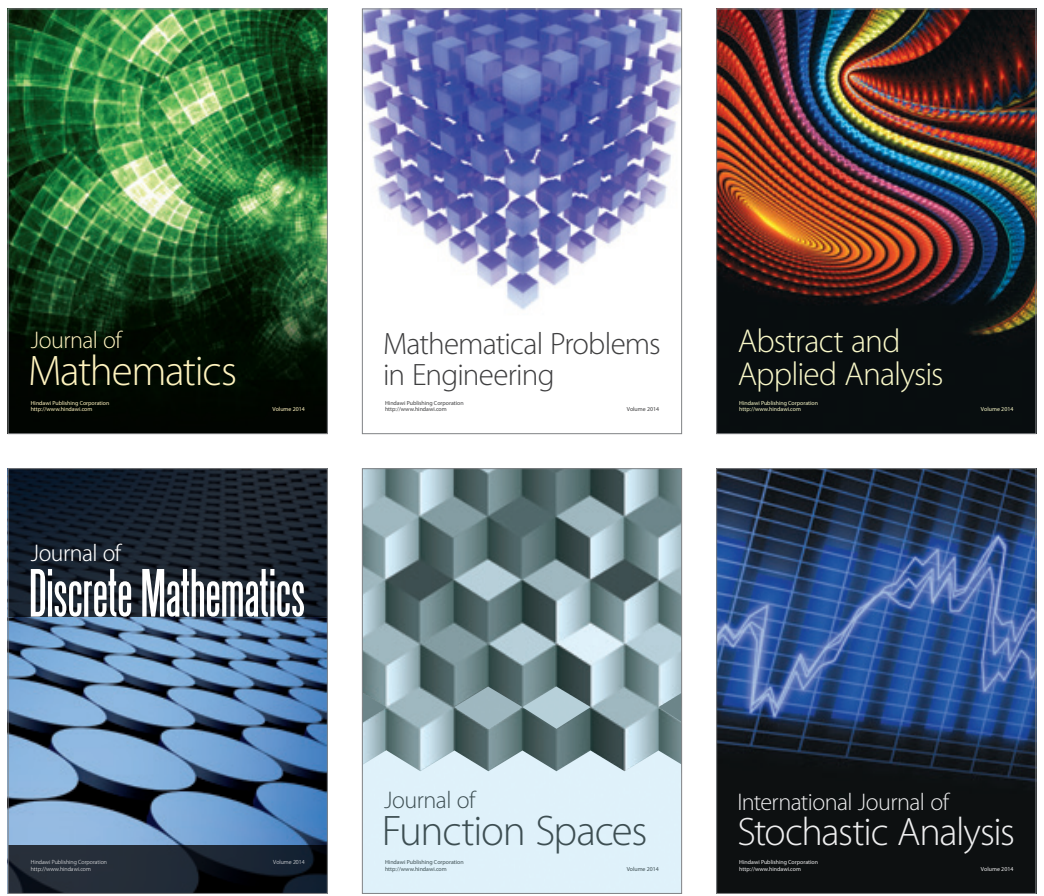

Journal of

Function Spaces

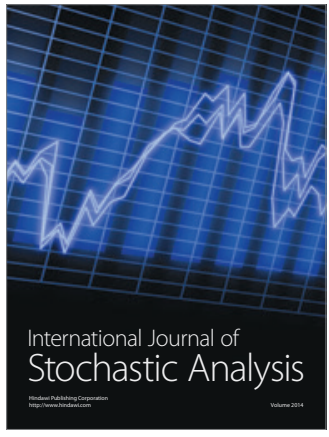

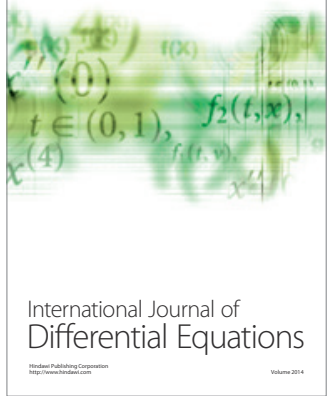
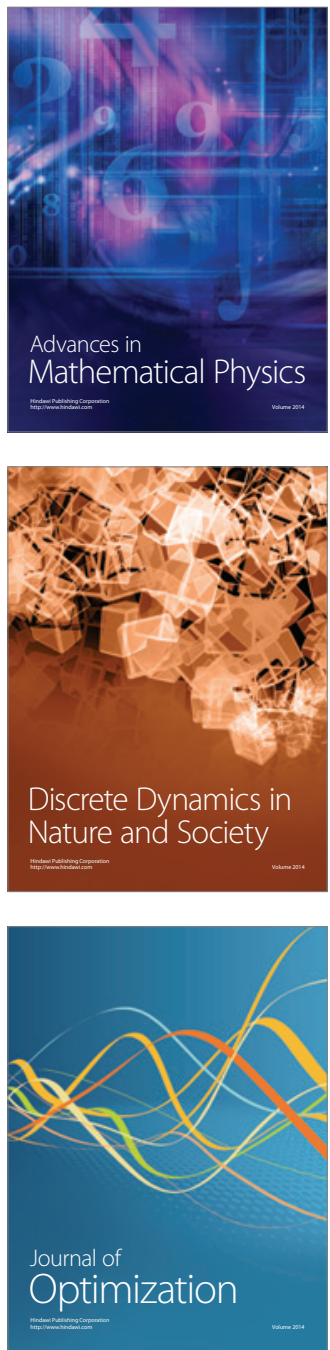